\title{
Different species of phosphatidic acid are produced during neuronal growth and neurosecretion
}

\author{
Emeline Tanguy ${ }^{1}$, Qili Wang ${ }^{1}$, Pierre Coste de Bagneaux ${ }^{1}$, Laetitia Fouillen ${ }^{2}$, Tamou Thahouly ${ }^{1}$, \\ Mohamed-Raafet Ammar ${ }^{1}$ and Nicolas Vitale ${ }^{1,3, *}$ \\ ${ }^{1}$ Institut des Neurosciences Cellulaires et Intégratives, CNRS UPR 3212, Université de Strasbourg, 5 rue Blaise Pascal, 67000 \\ Strasbourg, France \\ ${ }^{2}$ Laboratoire de Biogénèse Membranaire, UMR-5200 CNRS, Plateforme Métabolome, Université de Bordeaux, 33883 Villenave \\ D'Ornon, France \\ 3 INSERM, 75654, Paris cedex 13, France
}

Received 24 January 2018 - Accepted 15 March 2018

\begin{abstract}
Although originally restricted to their structural role as major constituents of membranes, lipids are now well-defined actors to integrate intracellular or extracellular signals. Accordingly, it has been known for decades that lipids, especially those coming from diet, are important to maintain normal physiological functions and good health. This is especially the case to maintain proper cognitive functions and avoid neuronal degeneration. But besides this empiric knowledge, the exact molecular nature of lipids in cellular signaling, as well as their precise mode of action are only starting to emerge. The recent development of novel pharmacological, molecular, cellular and genetic tools to study lipids in vitro and in vivo has contributed to this improvement in our knowledge. Among these important lipids, phosphatidic acid (PA) plays a unique and central role in a great variety of cellular functions. This article will review the different findings illustrating the involvement of PA generated by phospholipase D (PLD) and diacylglycerol kinases (DGK) in the different steps of neuronal development and neurosecretion. We will also present lipidomic evidences indicating that different species of PA are synthesized during these two key neuronal phenomena.
\end{abstract}

Keywords: exocytosis / neuroendocrine / neuron / phospholipase D / phosphatidic acid

Résumé - Différentes formes d'acide phosphatidique sont produites au cours de la croissance neuronale et la neurosécrétion. Bien qu'originalement restreints à leur rôle majeur de constituants principaux des membranes, il est maintenant communément admis que certains lipides possèdent également une fonction importante d'intégration des signaux intra- ou extra-cellulaires. En accord avec cette notion, cela fait des décennies qu'il est reconnu que les lipides, principalement via l'alimentation, jouent un rôle crucial dans le maintien de l'homéostasie de nombreuses fonctions physiologiques et dans la santé humaine au sens large. Ceci est particulièrement le cas pour la conservation d'un niveau optimal des fonctions cognitives et pour lutter contre la dégénérescence neuronale. Toutefois, malgré ces connaissances empiriques, la nature exacte des lipides impliqués, ainsi que les mécanismes d'action mis en jeu peinent à émerger. Le développement récent de nouveaux outils génétiques, moléculaires, et pharmacologiques pour étudier les lipides in vitro et in vivo permettent à présent d'améliorer nos connaissances. Parmi ces lipides, l'acide phosphatidique joue un rôle particulier et central dans diverses fonctions cellulaires essentielles. Cet article résume les observations récentes qui illustrent que l'acide phosphatidique, produit par deux voies enzymatiques distinctes impliquant les phospholipases D et les diacylglycérol-kinases, est impliqué dans le développement neuronal et la neurosécrétion. Pour finir, nous présentons des résultats d'analyses lipidomiques qui indiquent que différentes formes de l'acide phosphatidique sont produites au cours de ces deux processus neuronaux majeurs.

Mot clés : acide phosphatidique / exocytose / neuroendocrine / neurone / phospholipase D

*Correspondence: vitalen@inci-cnrs.unistra.fr 


\section{Introduction}

Normal brain function requires the establishment of specific neuronal networks mediated by synapses (i.e. structures allowing chemical or electrical communication between neurons). Indeed, during their development, neurons exhibit various morphological and structural changes including axon and dendrite outgrowth, dendritic branching and ramification and spine development that ultimately allow synapse formation and maintenance, which are critical events in the establishment of neuronal networks (Dotti et al., 1988). Further, neuronal development and maturation require plasma membrane expansion and rearrangement provided essentially by two membrane trafficking mechanisms: exocytosis and endocytosis (Gasman and Vitale, 2017). In a first part, exocytosis supports intracellular membrane supply required for the plasma membrane enlargement as well as neurotrophines receptor and neuronal adhesion molecules membrane expression that insure synapse formation and maintenance (Sytnyk et al., 2017). In a second part, endocytosis insures intercellular signal integration required as well for synaptic formation and specificity. Moreover, membrane lipids composition has emerged as an important player during membrane trafficking and cell signaling. Further, it is tempting to speculate that specific lipids and their dynamics are critically important for membrane reorganization and neuronal development.

Among all the lipids, phosphatidic acid (PA) appears to have a particular function in these membrane-related phenomena's. PA is the simplest glycerophospholipid and plays a key structural role as a precursor of most glycerophospholipids, but it is also considered as an important player in the transmission, amplification and regulation of a variety of intracellular signaling and cellular functions (Ammar et al., 2014). At the molecular level, this signaling PA could interact with various proteins to modulate their catalytic activity and/or their membrane association including GTPases, kinases, phosphatases, nucleotide binding proteins and phospholipases (Ammar et al., 2013a, 2014). Furthermore, many PA partners have been involved in the modulation of actin dynamics and membrane trafficking as well as neuronal development. In this article, we will describe and discuss our observations suggesting that PA contributes to the cellular and molecular mechanisms that govern neuronal development and neurosecretion. Moreover, we will present our recent findings suggesting that various PA species are differently synthetized during neurite outgrowth and neurosecretion.

\section{$2 \mathrm{PA}$ is involved in neurosecretion}

The PA biosynthetic pathway involves mostly three families of enzymes (Fig. 1): phospholipases D (PLD), diacylglycerol kinases (DGK), and lysophosphatidic-acyltransferases (LPAAT), which has made difficult accurate modulation of cellular PA to evaluate its contribution to neuronal function. Use of ethanol as an inhibitor of PA synthesis by PLD was at first probably the most used approach and has led to the notion that PLD-generated PA plays a role in various membrane trafficking events, especially during endocytosis and regulated exocytosis in different cell types

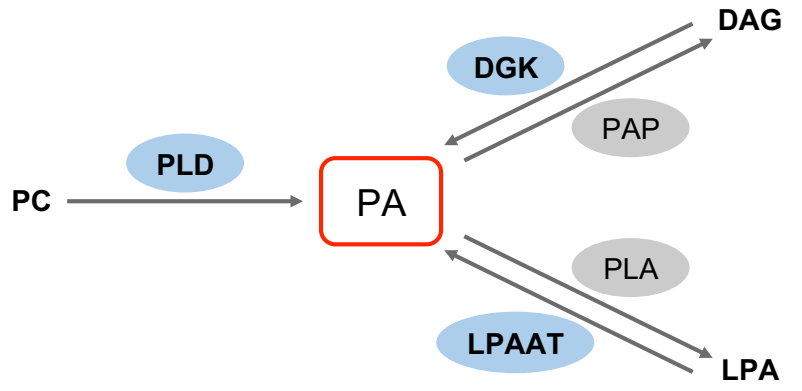

Fig. 1. Biosynthetic pathways of structural and signaling PA. PA is a central phospholipid for biosynthetic and signaling reactions. Enzymes in blue denote biosynthetic reactions that lead to structural and signaling PA synthesis whereas enzymes involved in PA catabolism are shown in grey.

including chromafin cells, neurons, epithelial and mast cells (Caumont et al., 1998; Bader and Vitale, 2009; Ammar et al., 2013a; Kassas et al., 2017; Tanguy et al., 2016,2018). Molecular tools and pharmacological inhibitors of PLDs have indicated that among PLDs, PLD1 is the isoform mostly involved in membrane trafficking. It must be noted however, that DGK-generated PA has been reported to be involved as well in membrane trafficking (Lopez et al., 2012).

Chromaffin cells are neuroendocrine cells originating from the neural crest and have taken a prominent place in the models that have provided important insight into the molecular machinery underlying the successive steps of neurosecretion and exocytosis at large (Bader et al., 2002). Thus, by offering the opportunity to combine the use of recent electrophysiological and biophysical techniques allowing single-vesicle resolution together with specific biochemical modifications in the machinery involved in exocytosis, chromaffin cells allowed the identification of most molecular players that orchestrate the formation, targeting, docking, and fusion of secretory granules. In fact, our early evidence obtained from chromaffin cells injected with a dominant-negative PLD1 mutant supported a function for PLD1-generated PA in the late steps of exocytosis, such as membrane fusion and/or pore expansion (Vitale et al., 2001). Similarly, injection in Aplysia neurons blocked ACh release by reducing the number of active presynaptic releasing sites supporting evidence that PLD1 also plays a major role in neurotransmission, most likely by controlling the fusogenic status of presynaptic release sites (Humeau et al., 2001). Later, PLD1 silencing experiments reinforced this model as a decrease in the fusion rate of single secretory granule release was observed (Zeniou-Meyer et al., 2007). Interestingly, RSK2 was shown to be an important regulator of PLD1 activity in neurosecretion (Vitale, 2010). Since loss-of-function mutations of RSK2 are responsible for the Coffin-Lowry syndrome (CLS), an X-linked inherited mental retardation disease, the later observations suggest that the symptoms of CLS could result from alteration of neuronal development but also neuronal activity (Zeniou-Meyer et al., 2008). Using similar tools, PLD1-generated PA was also reported to contribute actively to the regulated secretion of insulin from $\beta$-pancreatic cells (Waselle et al., 2005), and of von Willebrand factor from endothelial cells (Disse et al., 2009). Another established role for PA in secretion relates to 
the induction of neutrophil exocytosis from azurophilic granules by anti-neutrophil cytoplasmic antibodies (Williams et al., 2007). Moreover, the ability of apicomplexan parasites to invade and later exit infected cells relies on specialized organelles termed micronemes that release their contents including adhesins, perforins and proteases in a PA-dependent manner (Bullen et al., 2016).

Yet, the mechanism(s) by which PA promotes membrane fusion remains debated. It may be linked to its ability to generate membrane curvature and facilitate fusion, modulate specific protein activity involved in the docking of vesicles and/or recruit key proteins required for the fusion process (Tanguy et al., 2018). The most widely accepted model for membrane fusion involves a combination of protein and lipid elements at the fusion site. Cone-shaped lipids, such as PA, have been proposed to facilitate fusion through their intrinsic negative curvatures when accumulating in the inner (cis) leaflets of contacting bilayers. Furthermore, PA forms highly charged microdomains, which serve as membrane insertion sites for numerous proteins important for exocytosis (Lam et al., 2008) and could induce conformational changes in associated proteins (Iversen et al., 2015). More directly, PA has been proposed to contribute to many biological processes through its ability to interact with positively charged domains of numerous proteins (Jenkins and Frohman, 2005). Finally, PA can also directly serve as source for synthesis of DAG, or activate PI-5 kinase producing $\operatorname{PtdIns}(4,5) \mathrm{P}_{2}$, both lipids playing positive function in exocytosis.

\section{PA is involved in neuronal outgrowth and development}

Ethanol as an inhibitor of PA synthesis by PLDs was also widely used in the field of neuron development and has led to a well-accepted model where PLD-generated PA is crucial to neurite outgrowth in a variety of neuronal cell models (Kanaho et al., 2009). In agreement with this model, we recently observed that neuronal maturation was significantly delayed in cortical Pld1 knockout neurons culture (Ammar et al., 2013b). However, the mechanisms implicating PA in the underlying membrane trafficking events remained elusive. Using the cell culture models of PC12 cells treated by neuronal growth factor (NGF), which have been widely used as a model to assess neurite outgrowth, we found that the PA sensor Spo20p-GFP accumulated at the plasma membrane following NGF stimulation as well as at the tips of growing neurites. Moreover, we found that PLD1 inhibition abolished PA accumulation induced by NGF, suggesting that PLD1 activation mediates PA synthesis in this process (Ammar et al., 2013b). Interestingly, we found that PLD1 is associated to the trans Golgi-derived vesicular structures containing VAMP-7/TiVAMP, a SNARE protein involved in neurite outgrowth (Martinez-Arca et al., 2000). Moreover, we have shown that PLD1 positive-vesicles move anterogradly and retrogradly in the developing neurites and accumulate at the growth cone (Ammar et al., 2013b). Furthermore, we found that the specific PLD1 inhibitors dramatically reduced membrane supply required for neurite outgrowth by reducing the fusion rate of these VAMP-7 positive vesicles (Ammar et al., 2013b). This appears as the first direct involvement of
PA-mediated membrane trafficking in neurite outgrowth (Fig. 2). Of note, expression of the PA sensor Spo20-GFP in PC1 2 cells strongly reduces the number and length of the NGFinduced neurites most likely as a consequence of PA quenching by the probe (Ammar et al., 2013b). It is thus tempting to speculate that PA acts in part by recruiting key proteins at the vesicle fusion site during neurite outgrowth (Fig. 2).

Pld1 knockout also affects a later step in neuronal development with a specific reduction in the number of secondary branching dendrites in cortical neurons. Additionally, the density of the spines, the tiny protrusions $(0.5 \mu \mathrm{m}$ wide, $2 \mu \mathrm{m}$ long) on neuronal dendrites that receive the majority of excitatory synaptic inputs, is significantly reduced in $\mathrm{Pldl}^{-/-}$cortical neurons and this reduction in spine density specifically affects mushroom and branched spines, which are the forms of mature spines (Ammar et al., 2013b). Accordingly, a previous report showed that the GTPase RalB promotes branching through a pathway involving PLD (Lalli and Hall, 2005). Altogether, these results imply critical functions of PLD1-produced signaling PA in early stages of neuronal growth and development, largely through an effect on cytoskeleton organization (Fig. 2). Intriguingly we found that neurons cultured from mice lacking ribosomal S6 kinase 2 (Rsk2), a model for the CLS (Humeau et al., 2009), exhibit a significant delay in growth in a similar way to that shown by neurons cultured from Pld1 knockout mice (Ammar et al., $2013 b$ ). Furthermore, gene silencing of $R s k 2$ as well as acute pharmacological inhibition of RSK2 in PC12 cells strongly impaired NGF-induced neurite outgrowth like it was found after Pld1 silencing or PLD1 inhibition (Ammar et al., 2013b). Expression of phosphomimetic PLD1(T147D) or PLD1 (T147E) mutants rescued the inhibition of neurite outgrowth in PC12 cells silenced for RSK2, revealing that PLD1 is a major target for RSK2 in neurite formation and allowing us to propose that the loss of function mutations in RSK2 that leads to CLS and neuronal deficits are related to defects in neuronal growth due to impaired RSK2-dependent PLD1 activity resulting in a reduced vesicle fusion rate and membrane supply. On the other hand, we also found that PLD1 regulates BDNF signaling endosomes in cortical neurons via ERK1/2 and CREB. This effect could explain in part the reduction of dendritic ramification observed in $\mathrm{Pldl}^{-/}$cortical neurons (Ammar et al., 2015).

PA generated by DGK also seems to modulate dendrite ramification and spines maturation. For instance, overexpression of wild-type DGK $\beta$ promotes dendrite outgrowth and spine maturation in transfected hippocampal neurons, whereas a kinase-dead mutant DGK has no effect (Hozumi et al., 2009). Accordingly, reduced number of branches and spines was found in primary cultured hippocampal neurons from DGK $\beta$ knockout compared to the wild type (Shirai et al., 2010). DGK $\zeta$ has also been reported to be important for the maintenance of dendritic spines and the regulation of the PA/DAG balance at excitatory synapses (Kim et al., 2009, 2010) (Fig. 2). Indeed the C-terminal PDZ-binding motif of DGK $\zeta$ interacts with the PDZ domains of the postsynaptic density protein PSD-95, an abundant postsynaptic scaffolding protein that regulates excitatory synaptic structure and function. This interaction promotes synaptic localization of DGK $\zeta$. Functionally, DGK $\zeta$ overexpression increases spine density in cultured hippocampal neurons in a manner that 

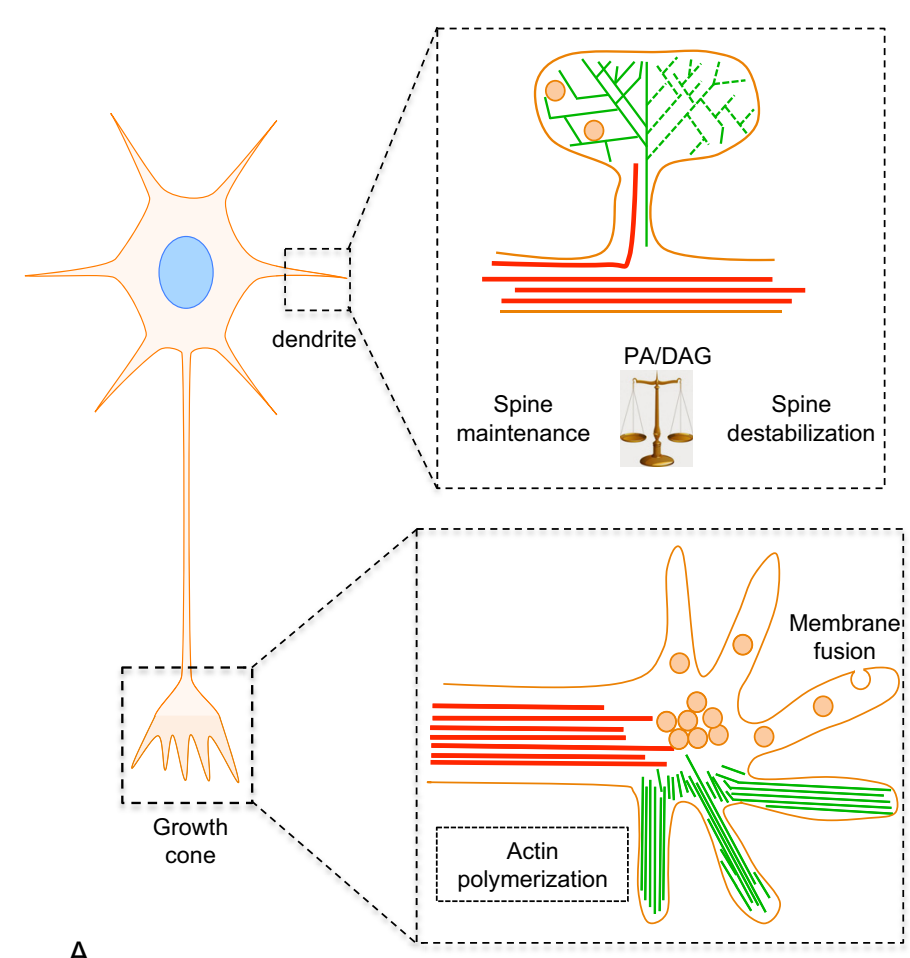

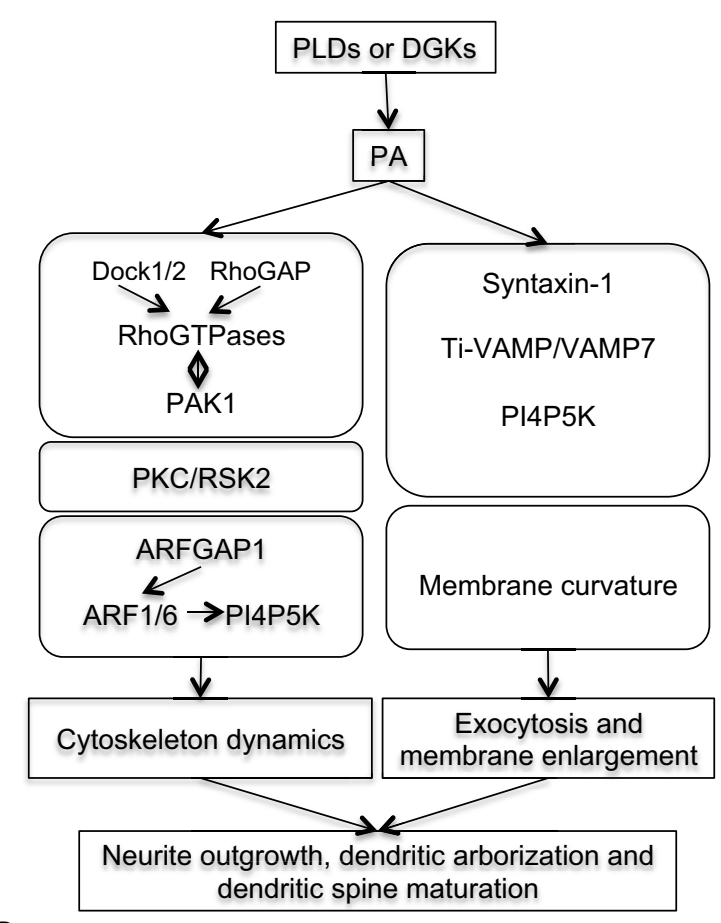

B

Fig. 2. $\mathrm{PA}$ is involved in axon and dendrite outgrowth, dendrite branching and spine formation. A) Schematic representation of growth cone and dendritic spines with actin cytoskeleton (green) and microtubules (red) as well as trafficking vesicles. In dendrites, PA/DAG balance controls the actin cytoskeleton dynamics whereas in growth cones, PA is involved in neurite outgrowth by controlling actin organization and vesicular trafficking for membrane supply. B) Examples of potential molecular targets of PA involved in cytoskeleton dynamics and vesicular exocytosis.

requires DGK catalytic activity but also PSD-95 binding, whereas knockdown of DGK $\zeta$ decreases spine density. Moreover, mice deficient for $d g k \zeta$ expression show a reduction in spine density in hippocampal CA1 pyramidal neurons and exhibit reduced excitatory synaptic transmission. Time-lapse imaging of $d g k \zeta$-deficient neurons revealed impaired spine maintenance but not formation (Kim et al., 2009). Finally, it was recently reported that $D g k \kappa$ silencing in CA1 region of mouse organotypic hippocampal slices causes a strong increase of abnormally long and multi-headed spines and a marked decrease of the proportion of mature spines whereas spine density remains unaffected (Tabet et al., 2016a). In addition, reduced $D g k \kappa$ expression accelerated spine turnover, as indicated by the increased rate of spine formation and elimination, associated with spine instability (Tabet et al., 2016a). Interestingly these structural defects are very similar to those previously observed in the $F m r l^{-/ y}$ mice, a model for fragile X syndrome (He and Portera-Cailliau, 2013), and it was shown that $D g k \kappa$ overexpression within $\mathrm{Fmrl}^{-/ \mathrm{y}}$ neurons could rescue the dendritic spine phenotype (Tabet et al., 2016a,b). Taken together, these data also reveal a key role of DGKgenerated PA in dendritic ramification and spine formation and maturation.

\section{PA synthesis during neurosecretion and neuronal growth}

Like all phospholipids, PA comes in different flavors based on the fatty acid composition. Indeed although in mammalian cells only saturated fatty acids are found in sn 1 position, in the sn2 position fatty acids can be saturated, mono-unsaturated, or poly-unsaturated. We performed a lipidomic analysis on cultured PC12 cells stimulated for exocytosis by a 10-minute incubation with a depolarizing $\mathrm{K}^{+}$solution to identify the different PA species produced during neurosecretion. The levels of medium and long carbon chains mono- and polyunsaturated forms of PA were increased after cell stimulation (Fig. 3). These results highlight the potential importance of different PA species in catecholamine secretion. In conclusion, the local build-up of different PA species together with other key lipids such PtdIns(4,5) $\mathrm{P}_{2}, \mathrm{DAG}$, and cholesterol presumably at the neck or near the fusion pore could contribute by changing membrane curvature, together with SNARE mediated membrane apposition and destabilization, to promote fusion pore formation and/or regulate its stability. It must also be noted that the contribution of PA in early steps of the secretory pathway has not been as well investigated (Gasman and Vitale, 2017).

Similarly, we performed a lipidomic analysis on cultured PC12 cells treated with NGF for 3 days. Among the 10 most abundant PA species detected, a specific increase in the long carbon chain forms 38:1, 38:2 and 40:6 was found, whereas levels of other PA especially saturated ones were not modified (Fig. 3). This observation therefore suggests that monounsaturated, bis-unsaturated, and/or the omega 3 polyunsaturated forms of PA contribute to neurite outgrowth and neuronal development. In line with this finding, it has been known for a long time that dietary omega 3 poly-unsaturated lipids such as docosahexanoicacid (DHA) and eicosapentae- 

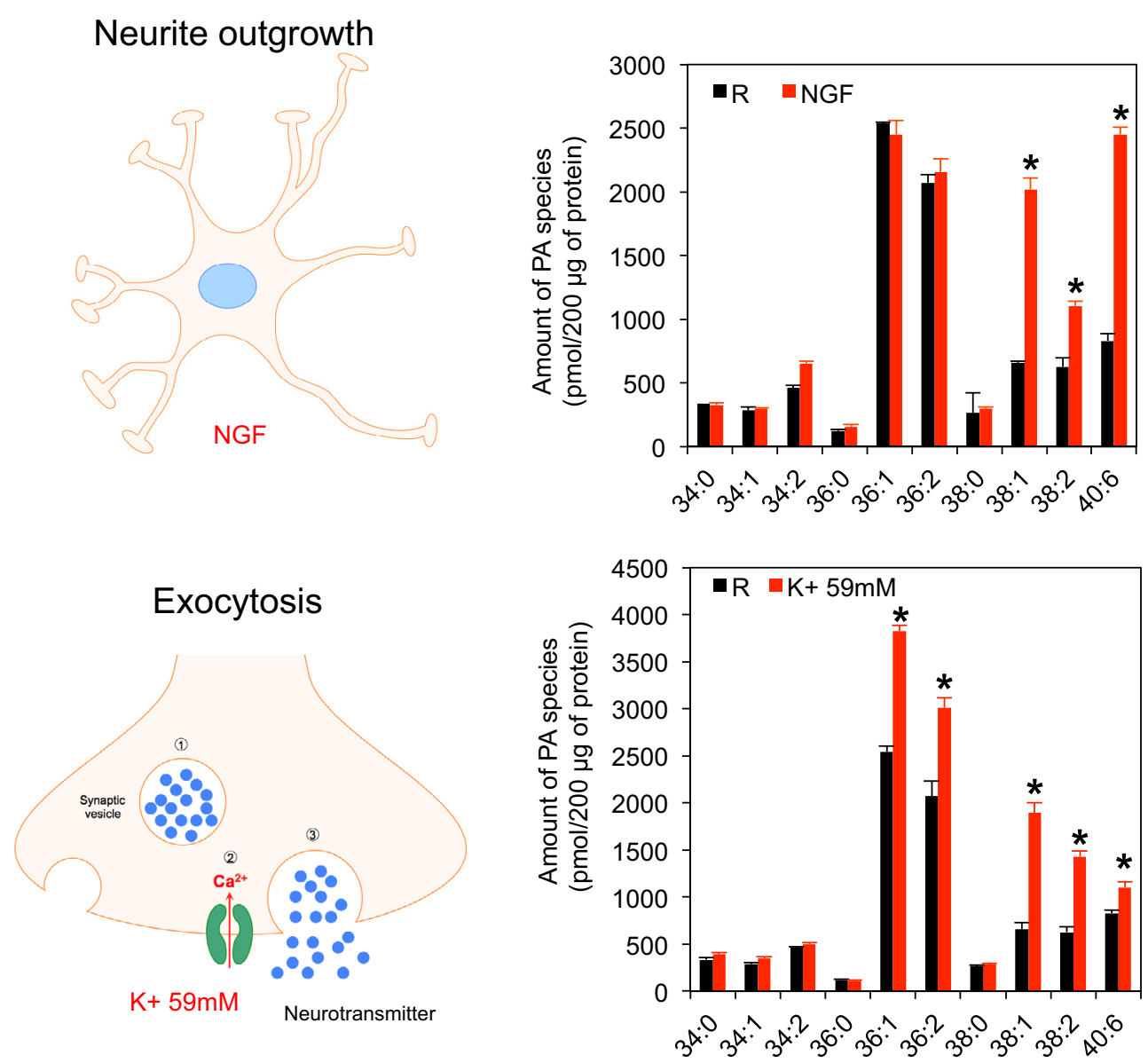

Fig. 3. Synthesis of different PA species during neurosecretion and neurite outgrowth. PC12 cells were either treated with $10 \mu \mathrm{M}$ of NGF for 3 days to stimulate neurite outgrowth (Ammar et al., 2013a,b) or with a $59 \mathrm{mM}$ potassium solution for 10-minutes to stimulate catecholamine neurosecretion (Béglé et al., 2009). Cells were washed with ice cold PBS, before being lyzed as described previously (Vitale et al., 2002). Proteins levels were quantified and levels of 40 different PA species were estimated in $200 \mu \mathrm{g}$ fractions by lipidomic analysis (Kassas et al., 2017). The levels of the 10 most abundant PA species are shown and expressed as pmol/200 $\mu \mathrm{g}$ of proteins. The total carbon chain length and saturation is indicated for each PA species. Results were obtained from 3 independent experiments $\left({ }^{*} p<0.001\right)$.

noic acid (EPA) have a beneficial cognitive effects (Cardoso et al. 2016). Although many important functions for the brain have been attributed to DHA for instance, the mechanism of its incorporation into glycerophospholipids is unknown. Of interest, lysophosphatidic acid acyltransferases 4 (LPAAT4) has been recently suggested to play a role for maintaining DHA in neural membranes (Eto et al., 2014). A combination of lipidomic approach and specific inhibitors for the multiple families of enzymes involved in the production and metabolism of PA will be helpful to define more precisely the nature of distinct PA species involved in the different steps of neuronal development and activity.

\section{Conclusion}

In this paper, we investigated the possibility that the fattyacyl chain composition affects the functions of PA in neuronal development and exocytosis, an aspect of PA that has not been investigated with care yet. For instance, do the various PAs displaying saturated, mono-, bi- or poly-unsaturated fatty acids have similar effects on membrane topology or recruit the same proteins? These questions are especially relevant in the context of neuronal development and degeneration, since many studies have highlighted key functions of dietary lipids in human cognitive activity (Tolias et al., 1998; Haast and Kiliaan 2015). We indeed found that neurite outgrowth and neurosecretion stimulation increased levels of multiple PA species. Interestingly, however, some of these increased PA species are similar and some others are not, suggesting that convergent and divergent mechanisms involving these different PA forms are present in these two important neuronal processes. The numerous genetic models now available, the recent progress in lipidomics, and some novel tools to study PA's function will be helpful to clarify the intriguing questions raised by these findings.

This work also opens new avenue on the possible contribution of PA and enzymes involved in PA synthesis in various neuronal pathologies such as Alzheimer's disease and autism spectrum disorders. In line with this possibility, the group of Gil di Paolo reported that PLD2 knockdown efficiently prevented cognitive loss in a mice model of 
Alzheimer's disease (Oliveira et al., 2010). Finally, the findings that an alteration of DAG/PA balance could be responsible for some of the symptoms of fragile $\mathrm{X}$ syndrome (Tabet et al., 2016a,b), also points to perturbation of PA synthesis as a major source of neuronal malfunction.

Acknowledgments. This work was supported by grants from "La Ligue Contre le Cancer" and from "Fondation pour la Recherche Médicale" to NV. The Metabolome facility of Bordeaux was supported by the grant MetaboHUB-ANR-11INBS-0010.

\section{References}

Ammar MR, Humeau Y, Hanauer A, Nieswandt B, Bader MF, Vitale N. 2013a. The Coffin-Lowry syndrome-associated protein RSK2 regulates neuritis outgrowth through phosphorylation of phospholipase D1 (PLD1) and synthesis of phosphatidic acid. $J$ Neurosci 33(50): 19470-19479.

Ammar MR, Kassas N, Chasserot-Golaz S, Bader MF, Vitale N. 2013b. Lipids in regulated Eexocytosis: what are they doing? Front Endocrinol (Lausanne) 4: 125.

Ammar MR, Kassas N, Bader MF, Vitale N. 2014. Phosphatidic acid in neuronal development: a node for membrane and cytoskeleton rearrangements. Biochimie 107: 51-57. DOI: 10.1016/j.bio chi.2014.07.026.

Ammar MR, Thahouly T, Hanauer A, Stegner D, Nieswandt B, Vitale N. 2015. PLD1 participates in BDNF-induced signalling in cortical neurons. Sci Rep 5: 14778.

Bader MF, Vitale N. 2009. Phospholipase D in calcium-regulated exocytosis: lessons from chromaffin cells. Biochim Biophys Acta 1791(9): 936-941.

Bader MF, Holz RW, Kumakura K, Vitale N. 2002. Exocytosis: the chromaffin cell as a model system. Ann N Y Acad Sci 971: 178-83.

Béglé A, Tryoen-Tóth P, de Barry J, Bader MF, Vitale N. 2009. ARF6 regulates the synthesis of fusogenic lipids for calcium-regulated exocytosis in neuroendocrine cells. J Biol Chem 284(8): 48364845 .

Bullen HE, Jia Y, Yamaryo-Botté Y, et al. 2016. Phosphatidic acidmediated signaling regulates microneme secretion in toxoplasma. Cell Host Microbe 19(3): 349-360.

Cardoso C, Afonso C, Bandarra NM. 2016. Dietary DHA and health: cognitive function ageing. Nutr Res Rev 29(2): 281-294.

Caumont AS, Galas MC, Vitale N, Aunis D, Bader MF. 1998. Regulated exocytosis in chromaffin cells. Translocation of ARF6 stimulates a plasma membrane-associated phospholipase D. $J$ Biol Chem 273(3): 1373-1379.

Disse J, Vitale N, Bader MF, Gerke V. 2009. Phospholipase D1 is specifically required for regulated secretion of von Willebrand factor from endothelial cells. Blood 113(4): 973-980.

Dotti CG, Sullivan CA, Banker GA. 1988. The establishment of polarity by hippocampal neurons in culture. J Neurosci 8(4): 1454-1468.

Eto M, Shindou H, Shimizu T. 2014. A novel lysophosphatidic acid acyltransferase enzyme (LPAAT4) with a possible role for incorporating docosahexaenoic acid into brain glycerophospholipids. Biochem Biophys Res Commun 443(2): 718-724.

Gasman S, Vitale N. 2017 Lipid remodelling in neuroendocrine secretion. Biol Cell 109(11): 381-390.

Haast RA, Kiliaan AJ. 2015. Impact of fatty acids on brain circulation, structure and function. Prostaglandins Leukot Essent Fatty Acids 92: 3-14.
He CX, Portera-Cailliau C. 2013. The trouble with spines in fragile X syndrome: density, maturity and plasticity. Neuroscience 251: $120-128$.

Hozumi Y, Watanabe M, Otani K, Goto K. 2009. Diacylglycerol kinase beta promotes dendritic outgrowth and spine maturation in developing hippocampal neurons. BMC Neurosci 10: 99.

Humeau Y, Vitale N, Chasserot-Golaz S, et al. 2001. A role for phospholipase D1 in neurotransmitter release. Proc Natl Acad Sci USA 98(26): 15300-15305.

Humeau Y, Gambino F, Chelly J, Vitale N. 2009. X-linked mental retardation: focus on synaptic function and plasticity. $J$ Neurochem 109(1): 1-14.

Iversen L, Mathiasen S, Larsen JB, Stamou D. 2015. Membrane curvature bends the laws of physics and chemistry. Nat Chem Biol 11(11): 822-825.

Jenkins GM, Frohman MA. 2005. Phospholipase D: a lipid centric review. Cell Mol Life Sci 62(19-20): 2305-2316.

Kanaho Y, Funakoshi Y, Hasegawa H. 2009. Phospholipase D signalling and its involvement in neurite outgrowth. Biochim Biophys Acta 1791(9): 898-904.

Kassas N, Tanguy E, Thahouly T, et al. 2017. Comparative characterization of phosphatidic acid sensors and their localization during frustrated phagocytosis. J Biol Chem 292(10): 42664279.

Kim K, Yang J, Zhong XP, et al. 2009. Synaptic removal of diacylglycerol by DGKzeta and PSD-95 regulates dendritic spine maintenance. EMBO J 28(8): 1170-1179.

Kim K, Yang J, Kim E. 2010. Diacylglycerol kinases in the regulation of dendritic spines. J Neurochem 112(3): 577-587.

Lalli G, Hall A. 2005. Ral GTPases regulate neurite branching through GAP-43 and the exocyst complex. J Cell Biol 171(5): 857-869.

Lam IP, Siu FK, Chu JY, Chow BK. 2008. Multiple actions of secretin in the human body. Int Rev Cytol 265: 159-190.

Lopez JA, Brennan AJ, Whisstock JC, Voskoboinik I, Trapani JA. 2012. Protecting a serial killer: pathways for perforin trafficking and self-defence ensure sequential target cell death. Trends Immunol 33(8): 406-412.

Martinez-Arca S, Alberts P, Zahraoui A, et al. 2000. Role of tetanus neurotoxin insensitive vesicle-associated membrane protein (TIVAMP) in vesicular transport mediating neurite outgrowth. $J$ Cell Biol 149(4): 889-900.

Oliveira TG, Chan RB, Tian H, et al. 2010. Phospholipase d2 ablation ameliorates Alzheimer's disease-linked synaptic dysfunction and cognitive deficits. J Neurosci 30(49): 1641916428.

Shirai Y, Kouzuki T, Kakefuda K, et al. 2010. Essential role of neuron-enriched diacylglycerol kinase (DGK), DGKbeta in neurite spine formation, contributing to cognitive function. PLoS One 5(7): e11602.

Sytnyk V, Leshchyns'ka I, Schachner M. 2017. Neural cell adhesion molecules of the immunoglobulin superfamily regulate synapse formation, maintenance, and function. trends. Neurosci 40(5): 295-308.

Tabet R, Moutin E, Becker JA, et al. 2016a. Fragile X mental retardation protein (FMRP) controls diacylglycerol kinase activity in neurons. Proc Natl Acad Sci USA 113(26): E36193628.

Tabet R, Vitale N, Moine H. 2016b. Fragile X syndrome: are signaling lipids the missing culprits? Biochimie 130: 188-194.

Tanguy E, Carmon O, Wang Q, Jeandel L, Chasserot-Golaz S, Montero-Hadjadje M, Vitale N. 2016. Lipids implicated in the 
journey of a secretory granule: from biogenesis to fusion. $J$ Neurochem 137(6): 904-912.

Tanguy E, Wang Q, Vitale N. 2018. Role of phospholipase D-derived phosphatidic acid in regulated exocytosis and neurological disease. Handb Exp Pharmacol. (in press).

Tolias KF, Couvillon AD, Cantley LC, Carpenter CL. 1998. Characterization of a Rac1-and RhoGDI-associated lipid kinase signaling complex. Mol Cell Biol 18(2): 76270.

Vitale N. 2010. Synthesis of fusogenic lipids through activation of phospholipase D1 by GTPases and the kinase RSK2 is required for calcium-regulated exocytosis in neuroendocrine cells. Biochem Soc Trans 38(1): 167-171.

Vitale N, Caumont AS, Chasserot-Golaz S, et al. 2001. Phospholipase D1: a key factor for the exocytotic machinery in neuroendocrine cells. EMBO J 20(10): 2424-2434.

Vitale N, Chasserot-Golaz S, Bader MF. 2002. Regulated secretion in chromaffin cells: an essential role for ARF6-regulated phospho- lipase D in the late stages of exocytosis. Ann N Y Acad Sci 971: 193-200.

Waselle L, Gerona RR, Vitale N, Martin TF, Bader MF, Regazzi R. 2005. Role of phosphoinositide signaling in the control of insulin exocytosis. Mol Endocrinol 19(12): 3097-3106.

Williams JM, Pettitt TR, Powell W, et al. 2007. Antineutrophil cytoplasm antibody-stimulated neutrophil adhesion depends on diacylglycerol kinase-catalyzed phosphatidic acid formation. $J$ Am Soc Nephrol 18(4): 1112-1120

Zeniou-Meyer M, Zabari N, Ashery U, et al. 2007. Phospholipase D1 production of phosphatidic acid at the plasma membrane promotes exocytosis of large dense-core granules at a late stage. J Biol Chem 282(30): 21746-21757.

Zeniou-Meyer M, Liu Y, Béglé A, et al. 2008. The Coffin-Lowry syndrome-associated protein RSK2 is implicated in calciumregulated exocytosis through the regulation of PLD1. Proc Natl Acad Sci USA 105(24): 8434-8439.

Cite this article as: Tanguy E, Wang Q, Bagneaux PCd, Fouillen L, Thahouly T, Ammar M-R, Vitale N. 2018. Different species of phosphatidic acid are produced during neuronal growth and neurosecretion. OCL 25(4): D408. 